\title{
POLÍTICA DE EDUCAÇÃO ESPECIAL NA REDE MUNICIPAL DE ENSINO DE BELO HORIZONTE-MG
}

\author{
POLÍTICA DE EDUCACIÓN ESPECIAL EN LA RED MUNICIPAL DE ENSEÑANZA \\ DE BELO HORIZONTE-MG
}

\author{
SPECIAL EDUCATION POLICY IN THE BELO HORIZONTE-MG MUNICIPAL \\ SCHOOL SYSTEM
}

\author{
Michele Aparecida de $\mathrm{SÁ}^{1}$ \\ Kamille VAZ ${ }^{2}$ \\ Taísa Grasiela Gomes Liduenha GONÇALVES ${ }^{3}$
}

RESUMO: Nesse artigo buscamos analisar a política de Educação Especial do município de Belo Horizonte-MG para compreendermos a organização dessa modalidade de ensino em sua rede e a articulação com as políticas nacionais. Para tanto, utilizamos da análise de documentação nacional e municipal que consideramos representativas da política de Educação Especial, e a análise dos dados do Censo Escolar (2018). Podemos constatar que historicamente a Educação Especial é caracterizada pelas disputas entre o público e o privado. Tanto no âmbito nacional como municipal houve uma tendência de direcionamento às instituições privado-assistenciais, possibilitando assim o financiamento público para rede privada. Os dados do censo escolar demostraram que a maior parte dos estudantes da Educação Especial estava matriculada nas escolas da rede municipal e $84 \%$ não frequentavam o AEE; além do número expressivo de matrículas de alunos com deficiência intelectual $(45,4 \%)$ e a existência de espaços segregados. Apesar dos entraves que a escola pública apresenta, consideramos ser nesse espaço que os estudantes têm acesso ao conhecimento sistematizado e, sendo assim, é nesse espaço onde os estudantes da Educação Especial devem estar.

PALAVRAS-CHAVE: Educação especial. Política de educação especial. Belo Horizonte. Censo escolar.

RESUMEN: En este artículo buscaremos analizar la política de Educación Especial del municipio de Belo Horizonte-MG para comprender la organización de esa modalidad de enseñanza en su red y la articulación con las politicas nacionales. Para ello, utilizamos del análisis de documentación nacional y municipal que consideramos representativas de la política de Educación Especial, y el análisis de los datos del Censo Escolar (2018).

1 Universidade Federal de Minas Gerais (UFMG), Belo Horizonte - MG - Brasil. Professora Adjunta do Departamento de Ciências Aplicadas à Educação. Doutorado em Educação Especial (UFSCAR). ORCID: https://orcid.org/0000-0001-8076-8383.E-mail: micheledesa20@hotmail.com

${ }^{2}$ Universidade Federal de Minas Gerais (UFMG), Belo Horizonte - MG - Brasil. Professora Adjunta do Departamento de Métodos e Técnicas de Ensino. Doutorado em Educação (UFSC). ORCID: https://orcid.org/0000-0003-2277-929X. E-mail: kamillevaz@gmail.com

${ }^{3}$ Universidade Federal de Minas Gerais (UFMG), Belo Horizonte - MG - Brasil. Professora do Programa de Pós-Graduação em Educação da FaE/DECAE. Doutorado em Educação Especial (UFSCAR). ORCID: https://orcid.org/0000-0001-5589-584X. E-mail: taisaliduenha@ufmg.br 
Podremos constatar que históricamente la Educación Especial se caracteriza por las disputas entre el público y el privado. Tanto en el ámbito nacional como municipal hubo una tendencia de direccionamiento a las instituciones privado-asistenciales, posibilitando asi el financiamiento público para la red privada. Los datos del censo escolar demostraron que la mayor parte de los estudiantes de la Educación estuvo matriculadas en las escuelas de la red municipal y 84\% no frecuentaban el AEE; además del número expresivo de matrículas de alumnos con discapacidad intelectual $(45,4 \%)$ y la existencia de espacios segregados. A pesar de los problemas que presenta la escuela pública, consideramos que es en ese espacio que los estudiantes tienen acceso al conocimiento sistematizado y, así, es en ese espacio en el que los estudiantes de la Educación Especial deben estar.

PALABRAS CLAVE: Educación escolar. Política de educación especial. Belo Horizonte.

Censo escolar.

ABSTRACT: In this paper we seek to analyze the Special Education policy of the municipality of Belo Horizonte-MG to understand the organization of this type of education in its network and the articulation with national policies. To do so, we used the analysis of national and municipal documentation that we consider representative of the Special Education policy, and the analysis of data from the School Census (2018). We can see that historically Special Education is characterized by disputes between public and private. Both nationally and at the municipal level, there has been a tendency to target private-assistance institutions, thus enabling public funding for the private network. The school census data showed that most students in Special Education were enrolled in municipal schools and 84\% did not attend AEE; besides the significant number of students with intellectual disabilities enrolled (45.4\%) and the existence of segregated spaces. Despite the obstacles that public school presents, we believe that this is the space where students have access to systematized knowledge and, therefore, this is the space where Special Education students should be.

KEYWORDS: Special education. Special education policy. Belo Horizonte. School census.

\section{Introdução}

Neste artigo temos a intenção de analisar a política de Educação Especial no município de Belo Horizonte, em Minas Gerais, com base em documentos oficiais e nos dados de matrículas dos microdados do Censo Escolar de 2018. Para tanto, faz-se necessário compreendermos, mesmo que de forma preliminar, alguns dos encaminhamentos políticos presentes nos documentos oficiais para a Educação Especial no país.

Desde a implantação do atendimento educacional aos alunos com deficiências há a coexistência de instituições públicas e o incentivo do Estado às iniciativas privadas (BUENO, 2011; JANNUZZI, 2012; KASSAR, 2013). Durante o início do século XXI, as disputas permanecem intensificadas em torno dos serviços a serem ofertados para os estudantes da 
Educação Especial, considerados os que apresentam deficiência, transtorno globais do desenvolvimento e altas habilidades/superdotação (BRASIL, 2013) .

Com a Política Nacional de Educação Especial na Perspectiva da Educação Inclusiva de 2008 (BRASIL, 2008) e a intensa divulgação da Educação Especial na escola regular, os grupos contrários a essa concepção pressionaram pela possibilidade de manutenção dos serviços especializados e do financiamento para as instituições privado-assistenciais. Em 2011, no governo de Dilma Rousseff (Partido dos Trabalhadores) foi aprovado o Decreto n. 7.611, de 17 de novembro de 2011, que regulamenta o Atendimento Educacional Especializado (AEE) nas escolas regulares. O Decreto em questão permite a realização do AEE nas instituições privado-assistenciais, retomando assim o seu financiamento (BRASIL, 2011).

Com o golpe jurídico-midiático-parlamentar que respaldou o Impeachment da presidente Dilma Rousseff e tornou presidente seu vice, Michel Temer (Movimento Democrático Brasileiro), a visão neoliberal para a educação se intensificou nas políticas educacionais, e com a Educação Especial não foi diferente. Desde 2018 o Ministério da Educação (MEC) iniciou um movimento de alteração da política de 2008. Durante o primeiro ano de governo do presidente Jair Messias Bolsonaro (sem partido) essa perspectiva de educação ganhou força, especialmente pelas instituições segregadas por tipo de deficiência. No dia 30 de setembro de 2020 foi publicado o Decreto Federal n. 10.502 (BRASIL, 2020), que instituiu a "nova" Política Nacional de Educação Especial, denominada Equitativa, Inclusiva e com Aprendizado ao Longo da Vida. Esta atual política apresenta a retomada da possibilidade de espaços segregados de ensino como escolas e classes especiais para os estudantes da Educação Especial.

Tais indicativos demonstram como a Educação Especial está e sempre foi fortemente marcada pelas disputas entre os que defendem o acesso à escola regular e os que defendem a possibilidade de as pessoas frequentarem exclusivamente instituições especializadas. Essas disputas e direcionamentos evidenciam a concepção de Educação Especial nacionalmente, mas também apresentam relação com as redes estaduais e municipais.

Dessa forma, compreender como as redes de ensino estão se organizando para atender os estudantes da Educação Especial na escola é essencial para entendermos como essa política está sendo encaminhada e quais as possibilidades de resistência e enfrentamentos podemos indicar, e, na contracorrente, defender a apropriação do conhecimento historicamente 
produzido pela humanidade. Buscamos evidenciar que o projeto de escola que lutamos para os estudantes da Educação Especial está além do acesso, mas da resistência a esse modelo de escola para o capital, buscando a garantia do direito à educação de qualidade socialmente referenciada para todos os estudantes.

Diante deste panorama, o objetivo deste estudo é analisar no município de Belo Horizonte - MG as políticas e os dados do censo escolar mais recente (2018) sobre a Educação Especial para compreendermos como esse município organiza essa modalidade de ensino em sua rede e como se articula com as políticas nacionais.

\section{Políticas de Educação Especial no município de Belo Horizonte}

$\mathrm{O}$ atendimento educacional às pessoas com deficiência no município de Belo Horizonte teve início na década de 1920 com a criação do Instituto São Rafael (1926), destinado ao atendimento das pessoas com deficiência visual, sendo essa uma iniciativa do governo estadual mineiro (COELHO, 2003).

As ações específicas da rede municipal de ensino de Belo Horizonte para o atendimento das pessoas com deficiência tiveram início no ano de 1982, com a criação de convênios com organizações privadas e filantrópicas. Os convênios eram firmados com instituições que atendiam os alunos matriculados na rede municipal de ensino e, em contrapartida, a Prefeitura de Belo Horizonte (PBH) disponibilizava professores para atuarem nestes espaços. Identifica-se que a modalidade de Educação Especial era realizada de forma terceirizada, a PBH utilizava as estruturas existentes de instituições privadas e/ou filantrópicas para oferecer o atendimento às crianças com deficiência (COELHO, 2003). Tal característica evidencia a forte parceria público-privada na educação do município.

No ano de 1984 foi promulgada a Lei n. 3.908, que autorizou a criação de salas de recursos de atendimento específico por deficiência, especialmente equipadas nas escolas da rede municipal de ensino regular para a complementação da educação dos estudantes com deficiência visual, auditiva e física. As salas de recursos se caracterizavam da seguinte forma:

Por salas de recursos, entende-se instalações apropriadas para o desenvolvimento de atividades pedagógicas, orientadas por um professor, que não podem ser realizadas nas salas de aulas comuns, já que trabalham para superar dificuldades específicas derivadas das limitações sensoriais e físicas dos alunos (BELO HORIZONTE, 1984).

Com relação ao atendimento ofertado, na legislação foi especificado que podia ser coletivo ou individual e deveria ser realizado antes ou depois do turno frequentado pelo aluno 
na sala regular. Destaca-se que nada foi assegurado, nesta legislação, para os estudantes com deficiência intelectual e Transtorno do Espectro Autista (TEA), por exemplo.

Após entrar em vigor a Constituição Federal de 1988, novas diretrizes foram traçadas para a educação brasileira, principalmente para a educação das pessoas com deficiência. Ficou estabelecido que a educação deve ocorrer preferencialmente na rede regular de ensino, com seguridade de um modelo de Atendimento Educacional Especializado (BRASIL, 1988, Art. 205 e 208).

Seguindo essa tendência, no governo do Prefeito Pimenta da Veiga/Eduardo Azeredo (Partido da Social Democracia Brasileira, 1989-1992), foi criada no município de Belo Horizonte a Lei n. 5.602 de 1989, que "Dispõe sobre matrículas de deficientes físicos em escola pública municipal”, para facilitar o acesso desse público. Neste mesmo ano foi criada a primeira escola de Ensino Especial da rede municipal de educação, a qual consistia no atendimento às pessoas com deficiência e compartilhava o prédio com outras escolas regulares.

Segundo Coelho (2003), neste momento, a educação das pessoas com deficiência na rede municipal de ensino baseava-se no "Projeto Livre Trânsito", que orientou a criação das Escolas Especiais na PBH e previa:

O Projeto Livre Trânsito previa que o Centro de Educação Especial tivesse suporte pedagógico condizente com o público a ser atendido, estabelecesse uma relação dinâmica e participativa com a comunidade escolar, implementasse uma prática pedagógica em que o aluno fosse sujeito do processo de aprendizagem e, efetivamente abrisse espaço para o "trânsito livre dos educandos portadores de deficiência nas escolas municipais de Belo Horizonte" (SMED, 1989) (COELHO, 2003, p. 88).

Com a implementação desse projeto, outras iniciativas foram criadas para consolidar a Educação Especial no município: uma delas foi a criação de mais duas escolas municipais de Ensino Especial, como eram denominadas, para atendimento de pessoas com deficiência.

No período de 1993 a 1996, especificamente no governo de Patrus Ananias (Partido dos Trabalhadores), para compor a política de Educação Especial foram promulgadas três legislações destinadas aos alunos com deficiência. A primeira, Lei n. 6.590 de 1994, dispõe sobre a implantação de Ensino Especial nas escolas públicas municipais. De acordo com esta legislação, o município deveria adotar Sistema Especial de Ensino nas escolas municipais da rede pública, objetivando a integração e o atendimento adequado dos alunos com deficiência física (entendidos nesta lei como deficiência visual, auditiva ou psicomotora), mentais e com altas habilidades/superdotação (BELO HORIZONTE, 1994a). 
A segunda lei promulgada foi a Lei n. 6.70,1 de 1994, que objetivava a garantia de vagas escolares para os alunos com deficiências. No Artigo $1^{\circ}$ ficou garantido vagas para os alunos com deficiência nas escolas regulares e especiais do município de Belo Horizonte. Entretanto, em parágrafo único, ficou assegurado que os alunos seriam atendidos na rede municipal ou em escolas particulares conveniadas (BELO HORIZONTE, 1994b). A terceira legislação criada foi a Lei n. 6.726, também de 1994, que tornou obrigatória a construção de rampas com corrimão nas escolas públicas municipais, ou seja, tentativa de deixar as escolas acessíveis para atender os alunos com deficiência física (BELO HORIZONTE, 1994c).

Porém, o que aconteceu na prática, durante o governo do Prefeito Patrus Ananias, segundo Coelho (2003), foi a expansão do atendimento dos estudantes com deficiência na rede conveniada especializada, com o investimento público nas instituições privadoassistenciais, indicando processos de privatização da educação pública.

Em meados da década de 1990, movimentos internacionais direcionaram a concepção de educação para uma proposta "inclusiva". No governo do Prefeito Célio de Castro (Partido Socialista Brasileiro, 1997-2000), pretendia-se direcionar as ações da Educação Especial para o campo da educação inclusiva. Houve alguns indicativos da tentativa de romper com a política de convênios, contratos com as escolas particulares especiais e investir no atendimento no setor público. Entretanto, devido às pressões feitas pelas organizações privado-assistenciais e pelos familiares, os convênios e contratos foram mantidos. Nesse aspecto, dois problemas foram evidenciados: "primeiro ensino segregado em escolas que atendem especificamente ao público com deficiência e o segundo diz respeito ao custeamento de estabelecimentos privados pelo Poder Público" (COELHO, 2003, p. 107).

As discussões sobre a proposta de educação inclusiva se intensificaram a partir do ano de 2002, no governo de Fernando Pimentel (Partido dos Trabalhadores, 2002-2008). O parecer n. 060/2004, emitido pelo Conselho Municipal de Educação Belo Horizonte (CME), um órgão de caráter deliberativo, normativo e consultivo, teve a atribuição de elaborar diretrizes para a educação inclusiva. Em dezembro de 2002 foi constituída a Comissão Especial para a construção do Parecer sobre a Educação Especial para a rede municipal de ensino.

Foi expresso no parecer elaborado pela comissão (Parecer n. 060/04) que as escolas especiais nos moldes que atuavam deveriam ser entendidas como transitórias, pois entendiam que enquanto existir alunos matriculados em escolas com atendimento exclusivo não se trata de inclusão, ou seja, a comissão deixou expresso que o atendimento escolar dos alunos com deficiência deveria ocorrer nas escolas regulares, indicou a importância de se realizar 
formação dos profisssionais da educação e investir recursos públicos para adaptação dos espaços físicos, mostrou a necessidade de se criar equipes e serviços para o Atendimento Educacional Especializado (BELO HORIZONTE, 2004).

No ano de 2005, durante o governo do prefeito Fernando Pimentel (PT), foi promulgada a Lei n. 9.078, que estabeleceu a Política da Pessoa com Deficiência para o Município de Belo Horizonte. No Art. 50 ficou assegurado: “[...] no Sistema Municipal de Ensino, a inclusão escolar de crianças, jovens e adultos em todos os níveis e modalidades de ensino, garantindo-lhes o acesso, a permanência e uma educação de qualidade". Esta legislação apresenta avanços porque assegura que a educação das pessoas com deficiência deve acontecer no sistema regular de ensino, contudo não consegue romper com os contratos público-privados. No Art. 51 ficou estabelecido:

O atendimento educacional especializado dar-se-á, prioritariamente, no âmbito da rede pública e de forma complementar por meio de convênios de cooperação ou contratos, conforme legislação pertinente e de acordo com as disposições da Lei de Diretrizes e Bases da Educação Nacional - LDB (BELO HORIZONTE, 2005).

Verifica-se que o Atendimento Educacional Especializado dos estudantes com deficiência pode acontecer de forma complementar por meio de convênios ou contratos firmados com instituições não pertencentes ao município.

Com a divulgação da Política Nacional de Educação Especial na Perspectiva da Educação Inclusiva de 2008, o município, em adesão à proposta de educação inclusiva, cria a Portaria SMED n. 112, a qual "Fixa normas para organização e funcionamento do Atendimento Educacional Especializado - AEE na Rede Municipal de Educação de Belo Horizonte - RME/BH”. De acordo com a portaria, fica instituído o AEE como serviço educacional ofertado para estudantes com deficiência, transtornos do desenvolvimento ou altas habilidades, matriculados na Educação Infantil (4 a 5 anos) e no Ensino Fundamental, constituindo caráter complementar ou suplementar, não substitutivo à escolarização, e devendo ser oferecido em turno diferente daquele correspondente à escolarização regular. (BELO HORIZONTE, 2009).

No ano de 2014, durante o governo do prefeito Marcio Lacerda (Partido Socialista Brasileiro, 2009-2016), foi aprovada a Lei n. 10.788, de dezembro de 2014, a qual "Estabelece diretrizes para a inclusão educacional de alunos com deficiência; transtornos globais de desenvolvimento e altas habilidades/superdotação, e dá outras providências". No 
Artigo $1^{\circ}$ ficam estabelecidas diretrizes para os estudantes da Educação Especial; destacamos as seguintes:

I - instituição da Educação Especial na perspectiva inclusiva, na Educação Infantil e Ensino Fundamental da Educação Básica, preferencialmente em escolas regulares sem prejuízo de as escolas especiais ou classes especiais continuarem a prover a educação mais adequada aos alunos com deficiência que não possam ser adequadamente atendidos em turmas comuns ou escolas regulares;

II - garantir a permanência, a acessibilidade e o desenvolvimento escolar dos alunos com deficiência, transtornos globais do desenvolvimento, altas habilidades/superdotação e/ou dificuldades de aprendizagem;

III - qualificação continuada e especializada dos professores;

IV - prioridade de oferta de vagas aos alunos com deficiência em unidades escolares próximas à residência do aluno (BELO HORIZONTE, 2014).

Embora esta lei expresse em seu título que estabelece diretrizes para a inclusão educacional, verifica-se no inciso I a possibilidade de a educação dos estudantes com deficiência acontecer em espaços segregados de ensino, como escolas ou classes especiais, com a justificativa de ser mais adequada para alguns alunos. Ainda fica estabelecido que:

Art. $3^{\circ}$ - Fica o poder público autorizado a criar convênios, a realizar contratos ou qualquer parceria permitida pela Lei Federal $n^{\circ} 8.666$, de 21 de junho de 1993, bem como manter os já existentes, ampliando-os, se necessário, com escolas privadas de ensino especial e outros estabelecimentos privados, para prestar, complementar ou auxiliar os serviços previstos nesta lei (BELO HORIZONTE, 2014).

Percebe-se que a política de Educação Especial no município de Belo Horizonte apresenta conformidade com a LDBEN/1996 quando considera que a educação dos estudantes da Educação Especial deve ocorrer preferencialmente no ensino regular. Entretanto, evidencia-se que existem dois pontos que merecem tensionamento: o primeiro é referente à possibilidade de a educação destes estudantes acontecer em espaços segredados, como escolas e classes especiais e; o segundo é o investimento de recursos públicos em instituições privadas, o que prioriza a parceria público-privada no financiamento da educação.

Para compreender melhor como a Educação Especial está configurada nesse município específico, optamos por analisar os dados de matrícula do Censo Escolar de 2018, os mais recentes no momento do estudo, como indicativo para as análises dos encaminhamentos sobre a política de Educação Especial em Belo Horizonte-MG. 


\section{O censo escolar e seus desdobramentos nas políticas educacionais municipais}

Segundo a Lei $n^{0} 12.796$ (BRASIL, 2013), o recenseamento escolar da educação básica deve ser anual, abrangendo estudantes em idade escolar e jovens e adultos não concluintes em todos os municípios brasileiros. A coleta e as análises dos dados do censo escolar (escola, matrículas, docentes e turmas) possibilitam um amplo conjunto de indicadores, como por exemplo o Índice de Desenvolvimento da Educação Básica (IDEB), e direcionam o repasse de recursos do governo federal ${ }^{5}$. Nas palavras de Rezende e Jannuzzi (2008, p. 122):

O uso de sistemas de indicadores, ainda que longe de ser suficiente para efetividade das políticas públicas, potencializa a chance de sucesso, já que permite, em tese, a avaliação de resultados tecnicamente bem respaldados e diagnósticos sociais abrangentes e empiricamente referidos.

$\mathrm{Na}$ abrangência das políticas de inclusão, a Educação Especial se apresenta como um campo de conhecimento e de desenvolvimento de estudos e pesquisas sobre diversas temáticas, dentre elas os indicadores educacionais. Diante disso, identifica-se o censo escolar como "[...] uma ferramenta fundamental para que os atores educacionais possam compreender a situação educacional do país, das unidades federativas, dos municípios e do Distrito Federal, bem como das escolas e, com isso, acompanhar a efetividade das políticas públicas" ${ }^{\text {. }}$.

Deste modo, a partir do censo escolar da educação básica é possível aferir os dados sobre a Educação Especial; neste trabalho analisaremos as matrículas dos estudantes da Educação Especial no município de Belo Horizonte-MG no ano de 2018. Buscamos interpretar o banco de matrículas dos microdados do censo escolar da Educação Básica segundo as variáveis ${ }^{7}: 1$. código do município de Belo Horizonte; 2. tipos de necessidades educacionais especiais ${ }^{8}$ : cegueira, baixa visão, surdez, deficiência auditiva, surdocegueira, deficiência física, deficiência intelectual, deficiência múltipla, Autismo, Síndrome de Asperger, Síndrome de Rett, Transtorno Desintegrativo da Infância (TDI) e altas habilidades/superdotação; 3. Etapas de ensino; 4. Atendimento Educacional Especializado; 5. Código da entidade.

O município de Belo Horizonte tem uma população estimada, segundo dados do Instituto Brasileiro de Geografia e Estatística (IBGE) de 2010, de 2.375.151 habitantes, e

${ }^{5}$ Informações do endereço eletrônico. Disponível em: http://portal.inep.gov.br/web/guest/censo-escolar. Acesso em: 13 abr. 2020.

${ }^{6}$ Informações do endereço eletrônico. Disponível em: https://www.gov.br/inep/pt-br/areas-de-atuacao/pesquisasestatisticas-e-indicadores/censo-escolar. Acesso em: 04 dez. 2020.

${ }^{7}$ De acordo com o caderno de instruções do Inep (2018).

${ }^{8}$ Correspondem às matrículas de estudantes da Educação Especial. 
possui IDH 0,810 , considerado muito alto. Atualmente tem 1.370 escolas públicas e privadas. Com relação à rede municipal de ensino, objeto deste estudo, possui 322 escolas que oferecem as seguintes etapas de ensino: creche, pré-escola, anos iniciais e finais do Ensino Fundamental e Educação de Jovens e adultos (BRASIL, 2018).

De acordo com os dados do censo escolar de 2018, a cidade de BH possuía 590.305 matrículas, destas 4.837 (0,8\%) estavam em dependência federal, 196.416 (33,3\%) estadual, $220.584(37,4 \%)$ municipal e 168. $468(28,5 \%)$ privada. Por sua vez, as matrículas de estudantes da Educação Especial na cidade de BH estão concentradas na esfera municipal $(55,8 \%)$, seguida da estadual $(32,4 \%)$, privada $(11,5 \%)$ e federal $(0,3 \%)$.

Neste direcionamento, identificou-se que as matrículas dos estudantes da Educação Especial correspondem a 3,7\% na rede municipal em 2018. A seguir, apresenta-se a distribuição dessas matrículas na rede municipal de Belo Horizonte segundo as etapas de ensino $(2018)^{9}$.

Figura 1 - Distribuição das matrículas da Educação Especial na rede municipal de Belo Horizonte segundo as etapas de ensino, os tipos de deficiências, TGD e altas habilidades/superdotação (2018)

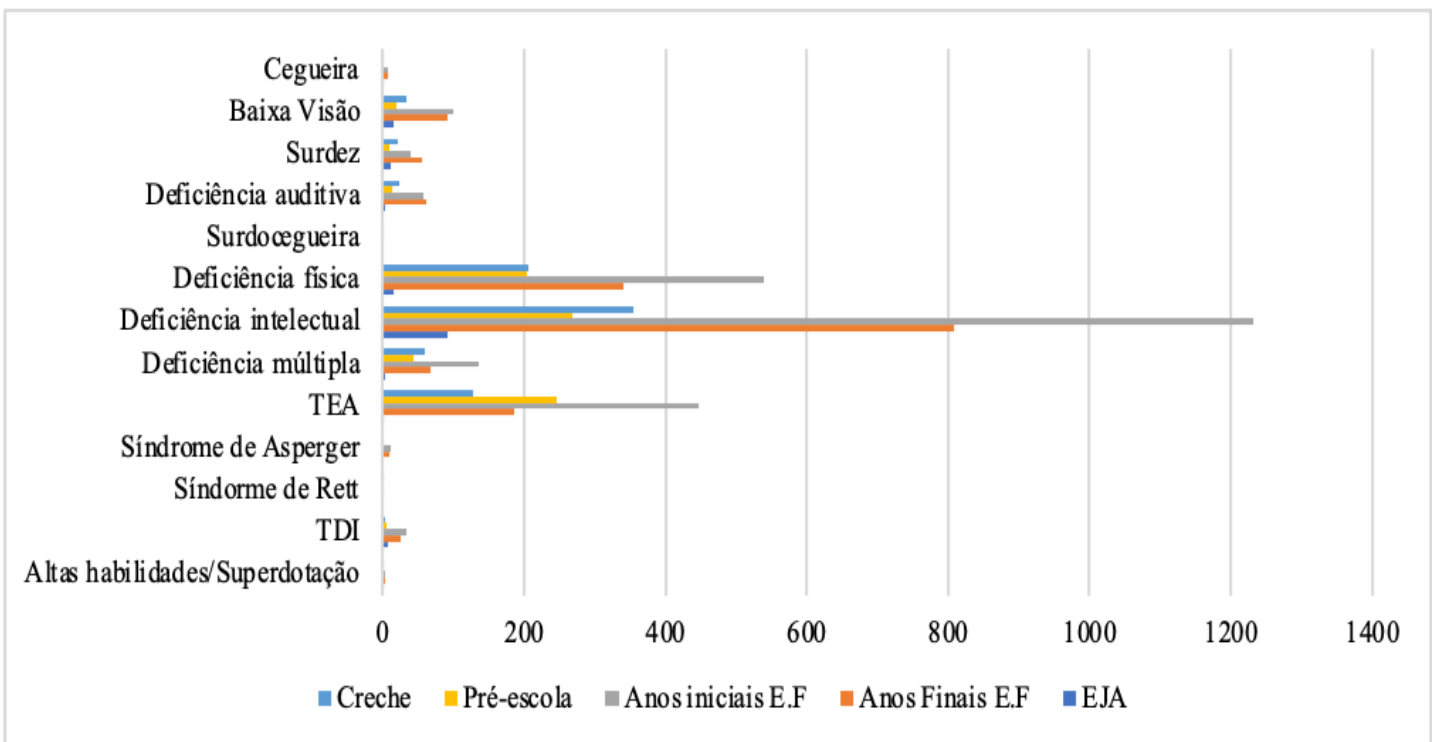

Fonte: Elaboração das autoras, com base no Censo da Educação Básica - INEP (BRASIL, 2018)

Verifica-se que as matrículas de estudantes com deficiência intelectual $(45,4 \%)$ é a que sobressai, seguida pela deficiência física $(21,5 \%)$ e TEA $(16,6 \%)$. Carneiro $(2017$, p. 91$)$ problematiza a deficiência intelectual, na perspectiva da psicologia histórico-cultural, como

9 Foram apresentados nesta Figura os microdados ofertados no censo escolar e identificou-se o "missing" dados que não foram computados, por exemplo, as matrículas da Figura 3 que não apresentaram as etapas de ensino.

RIAEE - Revista Ibero-Americana de Estudos em Educação, Araraquara, v. 16, n. esp. 2, p. 1343-1359, maio 2021. e-ISSN: 1982-5587 
uma produção social, e explica que “[...] tal condição não está dada ao nascer, mas vai se construindo e se consolidando na medida em que se oferece ambientes pouco desafiadores e práticas simplificadas, adaptadas à condição inicial apresentada por cada um desses sujeitos”. Neste direcionamento, Bridi e Souza (2017) problematizam os processos de identificação de estudantes com deficiência intelectual no contexto escolar baseados, por exemplo, na dificuldade acentuada na leitura ou escrita.

Os estudos de Meletti e Bueno (2011) e Meletti e Ribeiro (2014) no campo da Educação Especial pautados nos censos escolares aproximam-se aos achados deste estudo, também indicando a concentração das matrículas de estudantes com deficiência intelectual no âmbito nacional. Um dado que chama a atenção na rede municipal é o número de matrículas de estudantes com TEA, tendo em vista seu número expressivo. Apesar de não se tratar do foco de nossa pesquisa, destaca-se por considerar que esse dado merece ser aprofundado em outro momento.

Outra constatação que podemos aferir com os dados é sobre os anos iniciais do ensino fundamental ser a etapa de ensino que possui o maior número de estudantes da Educação Especial (43\%), seguida pelos anos finais do ensino fundamental $(27,3 \%)$, creche $(13,8 \%)$, pré-escola $(13,4 \%)$ e $\mathrm{EJA}^{10}(2,5 \%)$.

Cabe destacar os encaminhamentos das matrículas da Educação Especial para a EJA. Gonçalves, Bueno e Meletti (2013) indicam uma ampliação dessas matrículas no Brasil no período de 2007 a 2010, e apresentam a construção da denominada EJA Especial em instituições e classes especiais.

Com relação à oferta do Atendimento Educacional Especializado, identificou-se que, em média, $16 \%$ das matrículas de estudantes da educação da rede municipal realizaram o AEE que é garantido pelas legislações (BRASIL, 1988; 1996; 2011; 2015), conforme ilustra a figura 2.

${ }^{10}$ Anos iniciais e finais do ensino fundamental e ensino médio. 
Figura 2 - Matrículas da Educação Especial na rede municipal de Belo Horizonte, segundo o Atendimento Educacional Especializado (2018).

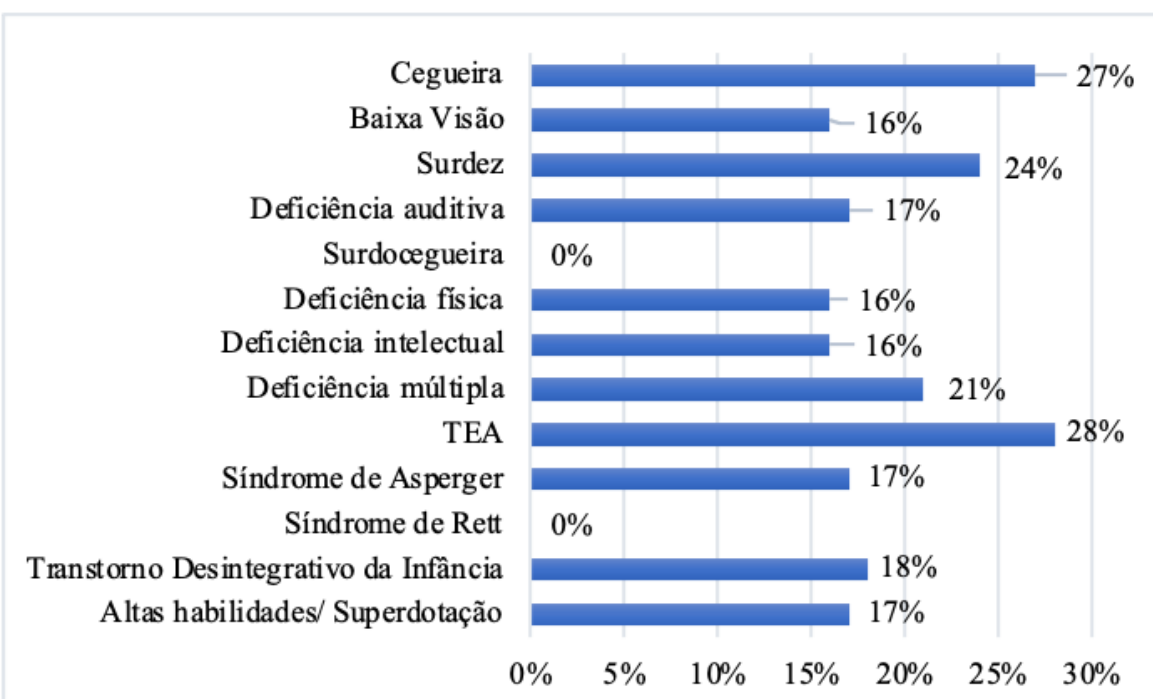

Fonte: Elaboração das autoras, com base no Censo da Educação Básica - INEP (BRASIL, 2018)

Os dados nos mostram que a maioria das matrículas (84\%) dos estudantes da Educação Especial da rede municipal não tem o direito efetivo com a participação no AEE.

Deparamo-nos com redes de ensino que mesmo possuindo legislações que, supostamente, garantiriam a educação dessas pessoas, apresentam dificuldades técnicas e pedagógicas do cotidiano escolar. Ilustra-se com a pesquisa de Carneiro, Michels e Garcia (2012), que ao analisarem o AEE na rede municipal de ensino de Florianópolis/SC demonstram as dificuldades de interlocução entre os professores regentes e os professores do AEE. Esses docentes possuíam contratos de trabalho precarizados, com turnos de trabalho divididos em diferentes escolas.

Outro estudo com o enfoque no AEE, realizado por Oliveira e Pletsch (2014), englobando quatro municípios da Baixada Fluminense-RJ, evidenciou que houve avanços legais, mas as redes de ensino enfrentam problemas com os serviços oferecidos pela Educação Especial, como efetividade do trabalho colaborativo entre os docentes da sala regular e do AEE, e indicam as fragilidades no que diz respeito ao desenvolvimento de habilidades cognitivas necessárias para a construção de conceitos científicos.

Com relação aos espaços para Atendimento Educacional Especializado, somente 19\% (60) das escolas municipais apresentam salas para o atendimento especial (BRASIL, 2018).

A rede municipal de ensino de $\mathrm{BH}$ possui três escolas de Ensino Especial que atende exclusivamente 430 matrículas de estudantes com deficiências e TEA, conforme apresenta a figura a seguir. 
Figura 3 - Matrículas de estudantes da educação especial em três escolas de ensino especial da rede municipal de $\mathrm{BH}$

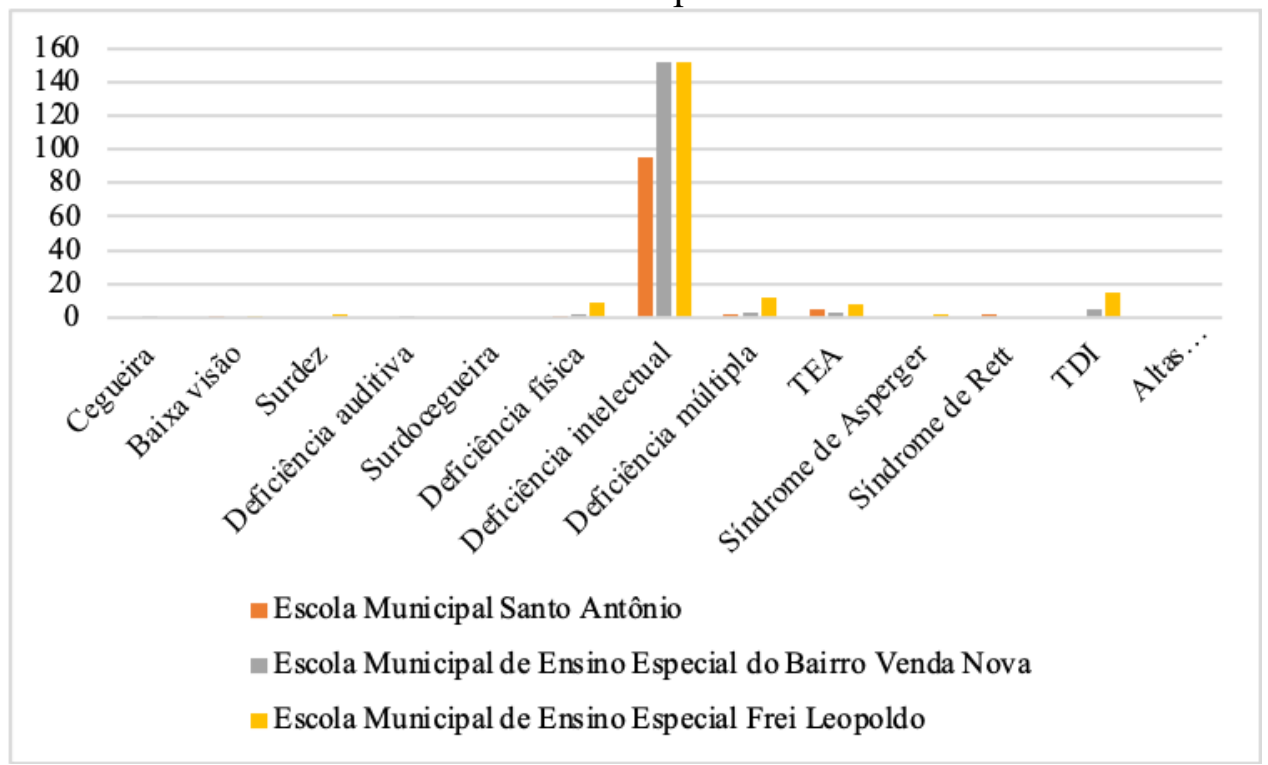

Fonte: Elaboração das autoras, com base no Censo da Educação Básica - INEP (BRASIL, 2018)

As matrículas em escolas de Ensino Especial correspondem a 5,3\% da rede municipal de $\mathrm{BH}$, com predomínio das matrículas de estudantes com deficiência intelectual $(84,1 \%)$, deficiência múltipla $(3,6 \%)$, TEA $(3,4 \%)$ e deficiência física $(2,5 \%)$. Entretanto, não foi possível identificar pelos microdados do censo escolar a distribuição das matrículas nestas três escolas de Ensino Especial segundo as etapas de ensino. Diante disso, considera-se relevante o desenvolvimento de pesquisas nestes espaços para compreender sua composição e os desdobramentos formativos para as pessoas que frequentaram.

\section{Considerações finais}

Com base nas discussões apresentadas neste artigo, podemos afirmar que a política de Educação Especial no município de Belo Horizonte-MG apresenta consonância com a política nacional, especialmente ao possibilitar atendimentos segregados em espaços privadoassistenciais ou em escolas especializadas ao longo da sua história.

Quando a política de Educação Especial na perspectiva inclusiva ganha destaque no cenário nacional a partir do início do século XXI, BH também investe em propostas inclusivas, entretanto, não consegue romper com a tradição de parcerias público-privadas e de escolas especializadas sob sua gestão. Identificamos neste estudo que a rede municipal de ensino possui três escolas especializadas que atendem 430 alunos em espaços segregados, situação essa oposta à proposta de educação inclusiva que assegura que os estudantes públicoalvo da Educação Especial devem ser matriculados nas escolas regulares. 
Os dados analisados com base nos microdados do Censo Escolar do ano de 2018 permitem afirmar que a maioria dos estudantes da Educação Especial matriculados nessa rede de ensino é identificada com deficiência intelectual, entretanto, esses mesmos dados revelam que a maior parte dos estudantes matriculados não tem acesso ao Atendimento Educacional Especializado, e os estudantes com deficiência intelectual estão entre os menos atendidos. Esse é um ponto que merece ser desenvolvido, pois, apesar de nos documentos oficiais constar a proposta de Educação Especial na perspectiva inclusiva, a maioria dos estudantes que acessam as escolas regulares não tem direito ao atendimento "carro-chefe" dessa mesma política.

Conscientes deste cenário político, econômico e social, apesar de todos os entraves que a escola pública apresenta, consideramos ser nesse espaço que, contraditoriamente, os estudantes têm potencial acesso ao conhecimento sistematizado e, sendo assim, é nesse espaço onde os estudantes da Educação Especial devem estar, sem perder de vista o projeto educacional que pautamos para todos os estudantes. Defendemos a escola pública, laica e gratuita como um direito de socialização do conhecimento formal e sistematizado, próprios da escola, possibilitando a emancipação humana e a luta para construir outra hegemonia que permita a superação de todas as desigualdades.

AGRADECIMENTOS: Pró-Reitoria de Pesquisa - UFMG.

\section{REFERÊNCIAS}

BELO HORIZONTE. SMED. Lei n. 3.908 de 1984. Cria salas de recursos nas escolas da rede municipal de ensino. Diário Oficial do Município, Belo Horizonte, MG, 1984.

BELO HORIZONTE. SMED. Lei n. 5.602 de 1989. Dispõe sobre matrículas de deficientes físicos em escola pública municipal. Diário Oficial do Município, Belo Horizonte, MG, 1989.

BELO HORIZONTE. SMED. Lei n. 6.590 de 1994. Dispõe sobre a implantação de Ensino Especial nas escolas públicas municipais. Diário Oficial do Município, Belo Horizonte, MG, 1994a.

BELO HORIZONTE. SMED. Lei n. 6.701 de 1994. Garante vagas escolares para os alunos portadores de deficiências. Diário Oficial do Município, Belo Horizonte, MG, 1994b.

BELO HORIZONTE. SMED. Lei n. 6.726 de 1994. Torna obrigatória a construção de rampas com corrimão nas escolas públicas municipais. Diário Oficial do Município, Belo Horizonte, MG, 1994c. 
BELO HORIZONTE. Conselho Municipal de Educação BH-MG-CME. Parecer 060 de 2004. Diretrizes para a Educação Inclusiva de Pessoas com Deficiência e Condutas Típicas. Belo Horizonte, MG: CME, 2004.

BELO HORIZONTE. SMED. Lei n. 9.078 de 2005. Estabelece a Política da Pessoa com Deficiência para o Município de Belo Horizonte e dá outras providências. Diário Oficial do Município, Belo Horizonte, MG, 2005.

BELO HORIZONTE. SMED. Portaria n 112, de 10 de julho de 2009. Fixa normas para organização e funcionamento do Atendimento Educacional Especializado - AEE na Rede Municipal de Educação de Belo Horizonte - RME/BH. Diário Oficial do Município, Belo Horizonte, MG, 17 jul. 2009.

BELO HORIZONTE. SMED. Lei n. 10.788, de dezembro de 2014. Estabelece diretrizes para a inclusão educacional de alunos com deficiência; transtornos globais de desenvolvimento e altas habilidades/superdotação, e dá outras providências. Diário Oficial do Município, Belo Horizonte, MG, 2014.

BRASIL. Constituição (1988). Constituição da República Federativa do Brasil. Brasília, DF: Senado Federal: Centro Gráfico, 1988. 292 p.

BRASIL. Lei n. 9.394, de 20 de dezembro de 1996. Lei de Diretrizes e Bases da Educação Nacional. Diário Oficial da União: Seção 1, Brasília, DF, n. 248, p. 27833, 23 dez. 1996. PL $1258 / 1988$

BRASIL. Política nacional de educação especial na perspectiva inclusiva. Brasília, DF: MEC/SEESP, 2008.

BRASIL. Decreto n· 7.611, de 17 de novembro de 2011. Dispõe sobre a educação especial, o atendimento educacional especializado e dá outras providências. Diário Oficial da União: Seção 1, Brasília, DF, p. 12, 18 nov. 2011.

BRASIL. Decreto n. 10.502, de 30 de setembro de 2020. Institui a Política Nacional de Educação Especial: Equitativa, Inclusiva e com Aprendizado ao Longo da Vida. Diário Oficial da União, Brasília, DF, 2020. Disponível em: https://www.in.gov.br/en/web/dou//decreto-n-10.502-de-30-de-setembro-de-2020-280529948. Acesso em: 5 dez. 2020.

BRASIL. Ministério da Educação. Instituto Nacional de Estudos e Pesquisas Educacionais Anísio Teixeira - INEP. Censo Escolar da Educação Básica - 2018. Disponível em: www.inep.gov.br/basica/levantamento/microdados.asp. Acesso em: 8 ago. 2020.

BRASIL. Lei n. 12.796, de 4 de abril de 2013. Que altera a Lei $n^{\circ} 9.394$, de 20 de dezembro de 1996, que estabelece as diretrizes e bases da educação nacional, para dispor sobre a formação dos profissionais da educação e dar outras providências. Brasília, DF, 5 abr. 2013. Disponível em: http://www.planalto.gov.br/ccivil_03/_Ato20112014/2013/Lei/L12796.htm\#art1. Acesso em: 12 abr. 2020.

BRASIL. Lei n. 13.146 de 06 de julho de 2015. Institui a Lei Brasileira de Inclusão da Pessoa com Deficiência (Estatuto da Pessoa com Deficiência). Brasília, DF, 7 jul. 2015. 
Disponível em: http://www.planalto.gov.br/ccivil_03/_ato2015-2018/2015/lei/113146.htm. Acesso em: 15 nov. 2020.

BRIDI, F. R. S.; SOUZA, B. W. A produção diagnóstica da deficiência mental/ intelectual no contexto escolar. In: CAIADO, K. R. M.; BAPTISTA, C. R.; JESUS, D. M. (Org.). Deficiência mental e deficiência intelectual em debate. Uberlândia: Navegando Publicações, 2017. v. 1, p. 241-264.

BUENO, J. G. S. Educação especial brasileira: questões conceituais e de atualidade. São Paulo: EDUC, 2011.

CARNEIRO, M. S.; MICHELS, M. H.; GARCIA, R. M. C. O caráter conservador da perspectiva inclusiva na educação especial: as salas multimeios na rede municipal de Florianópolis. Revista Cocar (UEPA), v. 6, p. 17-28, 2012.

CARNEIRO, M. S. Contribuições da abordagem histórico-cultural para a compreensão da deficiência intelectual como produção social. In: CAIADO, K. R. M.; BAPTISTA, C. R.; JESUS, D. M. (Org.). Deficiência mental e deficiência intelectual em debate. Uberlândia: Navegando Publicações, 2017. v. 1, p. 79-100.

COELHO, E. M. Trajetórias de construção de política pública: limites e possibilidade da inclusão escolar. 2003. 224 f. Dissertação (Mestrado em Administração Pública) - Escola de Governo, Fundação João Pinheiro. Belo Horizonte, 2003.

GONÇALVES, T. G. G. L.; BUENO, J. G. S.; MELETTI, S. M. F. Matrículas de alunos com deficiência na EJA: Uma análise dos indicadores educacionais brasileiros. Revista Brasileira de Política e Administração da Educação, v. 29, p. 407-427, 2013.

JANNUZZI, G. M. A educação do deficiente no Brasil: dos primórdios ao início do século XXI. 3. ed. Campinas, SP: Autores Associados, 2012.

KASSAR, M. C. M. Uma breve história da educação das pessoas com deficiências no Brasil. In: MELETTI, S. M. F.; KASSAR, M. C. M. (Org.). Escolarização de alunos com deficiências: desafios e possibilidades. Campinas: Mercado de Letras, 2013. v. 1, p. 33-76.

MELETTI, S. M. F.; BUENO, J. G. S. O impacto das políticas públicas de escolarização de alunos com deficiência: uma análise dos indicadores sociais no Brasil. Linhas Críticas (Online), v. 17, p. 367-384, 2011.

MELETTI, S. M. F.; RIBEIRO, K. Indicadores educacionais sobre a educação especial no Brasil. Cadernos CEDES, Campinas, v. 34, n. 93, p. 175- 189, 2014.

OLIVEIRA, M. C. P.; PLESTCH, M. D. Atendimento educacional especializado nas redes de ensino da Baixada Fluminense: um diálogo em construção. In: SEMINÁRIO INTERNACIONAL DE INCLUSÃO ESCOLAR: PRÁTICAS EM DIÁLOGO, 1., 2014, Rio de Janeiro. Anais [...] Rio de Janeiro, RJ: CAP/UERJ, 2014.

REZENDE, L. M.; JANNUZZI, P. M. Monitoramento do Plano de Desenvolvimento da Educação: proposta de aprimoramento do IDEB e de painel de indicadores. Revista do Serviço Público, Brasília, v. 59, p. 121-150, 2008. 


\section{Como referenciar este artigo}

SÁ, M. A.; VAZ, K.; GONÇALVES, T. G. G. L. Política de educação especial na rede municipal de ensino de Belo Horizonte-MG. Revista Ibero-Americana de Estudos em Educação, v. 16, n. esp. 2, p. 1343-1359, maio 2021. e-ISSN: 1982-5587. DOI: https://doi.org/10.21723/riaee.v16iesp2.15129

Submissão em: $15 / 12 / 2020$

Revisões requeridas em: $28 / 01 / 2021$

Aprovado em: 03/03/2021

Publicado em: 01/05/2021 